\title{
PENGARUH LATIHAN SENAM JANTUNG SEHAT SERI I TERHADAP PENINGKATAN KAPASITAS VITAL PARU BAGI PENSIUNAN WANITA P2TEL MEDAN
}

\author{
Indra Darma Sitepu', Muhammad Faisal Ansari Nasution ${ }^{2}$ \\ Fakultas Ilmu Keolahragaan, Universitas Negeri Medan \\ pieblux@gmail.com,faisalnst91@unimed.ac.id
}

\begin{abstract}
Abstrak: Tujuan dari penelitian ini untuk mengetahui pengaruh latihan Senam Jantung Sehat seri I terhadap peningkatan kapasitas vital paru bagi pensiunan wanita P2TEL Medan. Senam jantung sehat bertujuan untuk melatih jantung, maka setiap rangkaian gerakan haruslah mampu meningkatkan beban latihan, agar denyut nadi / jantung dan kapasitas vital paru terpelihara. Populasi dalam penelitian ini adalah pensiunan wanita usia di P2TEL Medan tahun 2019 dengan jumlah 52 orang. Dari hasil penelitian, dapat diperoleh data bahwa terjadi peningkatan kapasitas vital paru wanita usia lanjut yang signifikan, hal ini ditunjukkan dari hasil uji t dengan nilai thitung 3,68 > ttabel 2,46 pada taraf signifikansi 0,01. Rata- rata kapasitas vital paru sebelum mengikuti latihan adalah sebesar $946 \mathrm{ml}$ dan setelah latihan menjadi 1013,33 ml atau terjadi peningkatan sebesar $7,12 \%$. Berdasarkan hasil penelitian dapat disimpulkan bahwa Senam Jantung Sehat Seri I dapat mempengaruhi kapasitas vital paru pensiunan wanita P2TEL Medan. Latihan Senam Jantung Sehat Seri I memberikan kontribusi yang signifikan terhadap peningkatan kapasitas vital paru pensiunan wanita P2TEL Medan. Maka dapat disarankan pensiunan wanita P2TEL Medan untuk lebih termotivasi dalam melakukan kegiatan Jantung Sehat Seri I sebagai salah satu bentuk latihan dalam pembinaan kondisi fisik yang prima dalam menjaga tingkat kesegaran jasmani.
\end{abstract}

Kata Kunci : Senam Jantung Sehat Seri I, Kapasitas Vital Paru

\begin{abstract}
The purpose of this study is to find out the effect of series-1 healthy heart calisthenics on improvement of lung vital capacity for P2Tel Medan women pensioners in 2019. Healthy heart calisthenics aims to train the heart, so each series of movements must be able to increase the training load, so that the pulse and lung vital capacity is maintained. The populations in this study were women pensioners at P2TEL Medan in 2019 with a total of 52 people. From the results of the study, it obtained that there is a significant increase in the lung vital capacity of elderly women, this is indicated by the results of the $t$ test with a value of $3.68>2.46$ at the significance level of 0.01 . The average vital lung capacity before participating in the training was $946 \mathrm{ml}$ and after training it became $1013.33 \mathrm{ml}$ or an increase of $7.12 \%$. Based on the results of the study, it can be concluded that the Series-1 Healthy Heart calisthenics can affect the vital lung capacity of retired female P2TEL Medan. Series-1 Healthy Heart calisthenics make a significant contribution to increasing the vital lung capacity of retired women in P2TEL Medan. Then it can be suggested that female pensioners in P2TEL Medan should be more motivated to do Series-1 Healthy Heart calisthenics as a form of exercise in fostering excellent physical conditions in maintaining physical fitness levels.
\end{abstract}

Keywords: Series-1 Healthy Heart Calisthenics, Lung Vital Capacity

\section{PENDAHULUAN}

Salah satu tolak ukur kemajuan suatu bangsa seringkali dilihat dari angka harapan hidup penduduknya. Indonesia sebagai salah satu negara berkembang, memiliki angka harapan hidup penduduk yang semakin meningkat sejalan dengan meningkatnya taraf hidup dan pelayanan kesehatan kepada masyarakat. Menurut Kinsella dan Taeuber dalam R. Boedhi-Darmojo dan $\mathrm{H}$. Hadi Martono, peningkatan jumlah orang usia lanjut yang di Indonesia diperkirakan antara tahun 1990-2025 sebesar 414\% (2004: 3). Kondisi ini akan menempatkan Indonesia pada urutan ke-3 
yang memiliki populasi usia lanjut terbanyak di dunia pada tahun 2020, setelah Cina dan India. (Emma, S. Wirakusumah, 2002: 1). Hal ini dapat menimbulkan masalah sosial khususnya menyangkut masalah kesehatan dan kesejahteraan hidup warga usia lanjut apabila tidak ditangani dengan baik.

Menurut Constantinides dalam R. BoedhiDarmojo dan H. Hadi Martono, menua adalah suatu proses menghilangnya secara perlahan-lahan kemampuan jaringan untuk memperbaiki diri/mengganti dan mempertahankan struktur dan fungsi normalnya sehingga tidak dapat bertahan dan memperbaiki kerusakan yang diderita (2004: 7). Hal ini dipicu oleh laju peningkatan reaksi radikal bebas dan sistem penawar racun yang semakin berubah seiring berjalannya usia. Kecepatan proses penuaan pada setiap individu berbeda-beda tergantung sikap dan kemauan dalam mengendalikan proses penuaan. Dalam hal ini pola hidup seseorang akan memberikan andil yang cukup besar dalam proses penuaan. Tidak jarang seseorang yang telah berusia lanjut akan tetapi tetap semangat, energic, optimis dan tidak merasa tua bahkan selalu berusaha mempertahankan diri untuk dapat tampil muda. Ada juga yang sebaliknya mengalami penuaan dini, kelompok ini sering kali mengabaikan pola hidup dan membiarkan dirinya digerogoti oleh berbagai penyakit.

Bertambahnya usia manusia akan diikuti perubahan bentuk jaringan otot yang menyebabkan turunnya kemampuan otot dan fungsi organ yang lain, salah satunya mempengaruhi sistem pernafasan yang mulai berkurang dalam Kapasitas Vital Paru, Volume Maksimal Paru Ventilasi, Kapasitas Maksimal Pernafasan dan Pengambilan oksigen secara maksimal selama latihan. (Sugiyanto dan Sudjarwo, 1991:185). Pada wanita, proses menua umumnya diartikan penurunan daya tarik fisik (kecantikan) yang biasanya terungkap dalam timbulnya kecemasan akan berkurangnya perhatian suami yang dapat menimbulkan masalah kejiwaan. (DepKes RI, 1991:47).

Sering kali keberadaan pensiunan dan para lanjut usia dipersepsikan secara negatif, dianggap sebagai beban keluarga dan masyarakat sekitar. Kenyataan ini mendorong semakin berkembangnya anggapan bahwa semakin tua semakin banyak masalah kesehatan, para pensiunan dan lanjut usia juga cenderung dipandang masyarakat tidak lebih dari sekelompok orang yang sakit-sakitan. Persepsi ini muncul karena memandang pensiunan dan lanjut usia dari kasus lanjut usia yang sangat bergantung kepada orang lain serta sakit-sakitan. Untuk menjaga kesehatan baik fisik maupun kejiwaannya, para pensiunan lansia harus melakukan aktifitas-aktifitas yang berguna bagi kehidupannya. Pensiunan lansia tidak boleh terlalu bersantai dan semua serba dilayani oleh orang lain, sebab akan mendatangkan berbagai penyakit dan penderitaan, karena hanya akan menyebabkan para lansia tersebut cepat meninggal dunia (Sidiarto dalam Lilik, 2002).

Melihat kondisi yang telah dipaparkan di atas sangat jelas dibutuhkan perhatian dan pelayanan kesehatan yang intensif dan berkesinambungan, yang harus diberikan kepada pensiunan dan penduduk lanjut usia hal tersebut agar lansia dimasa tuanya menjadi lansia yang sehat, berguna bagi masyarakat sekitarnya, merasa bahagia dan sejahtera secara fisik, mental dan spiritual. Selain itu dengan melakukan aktifitas fisik berupa latihan yang dapat mencukupi kebutuhan oksigen yang diperlukan pada waktu kerja atau latihan maka diharapkan dapat memelihara dan meningkatkan kesegaran jasmani, karena oksigen tidak dapat disimpan sebagai persediaan dalam tubuh maka yang dapat dilakukan adalah menjaga dan meningkat kemampuan organ-organ tubuh yang berfungsi menyerap dan menyalurkan oksigen agar selalu dalam kondisi baik. Latihan fisik ini sifatnya aerobik, dalam hal ini salah satu latihan yang cocok untuk usia lanjut adalah Senam Jantung Sehat Seri I.

\section{Senam Jantung Sehat}

Senam jantung sehat adalah olahraga yang disusun dengan selalu mengutamakan kemampuan jantung, gerakan otot besar dan kelenturan sendi, serta upaya memasukkan oksigen sebanyak mungkin (SJS Seri I, 2003). Selain meningkatkanya perasaan sehat dan kemampuan untuk mengatasi stress, keuntungan latihan aerobik yang teratur adalah meningkatnya kadar HDL-C, menurunnya kadar LDL-C, menurunnya tekanan darah, berkurangnya obesitas, berkurangnya frekuensi denyut jantung saat istirahat dan konsumsi oksigen miokardium (MVO2), dan menurunnya resistensi insulin (Sylvia, 2005).

Senam jantung sehat terdiri dari 6 seri, dimana setiap seri dibedakan dari gerakan dan intensitas latihan. Senam jantung sehat seri I, berbeda dengan senam jantung sehat seri II, III, IV, V maupun seri VI, dimana semakin besar seri, beban latihan semakin tinggi. Seri II dapat dilakukan jika sudah mampu melakukan senam seri I, begitu juga seterusnya. Memberikan kelenturan otot dan sendi dapat menghilangkan kekakuan otot dan sendi tersebut dapat dihilangkan dengan memberikan senam jantung sehat dan senam-senam lainnya yang sesuai. Menambah kekuatan otot-otot pada tangan dan kaki. Dengan demikian maka senam jantung sehat adalah olahraga yang berintikan aerobik ditambah dengan olahraga yang dapat memberikan kelenturan, kekuatan dan peningkatan otot-otot secara mudah, murah, meriah, massal dan manfaat serta aman (Ariyanti, 2010).

Pengamatan berbentuk sederhana hanya menghitung denyut nadi akan tetapi kegunaannya sangat bermanfaat. Dosis yang diberikan disesuaikan dengan umur. Rumus yang mudah yakni rumus 200 
yaitu 200 dikurangi umur. Itulah nadi maksimal yang boleh dilakukan sewaktu melaksanakan latihan. Dari gambaran tersebut olahraga jantung sehat dapat dilakukan oleh siapa saja, dimana saja dan kapan saja (Supriyadi, 2006).

\section{Program Senam Jantung Sehat}

Di dalam buku petunjuk Senam Jantung Sehat Seri I (2003) dinyatakan, bahwa program olahraga jantung sehat dalam pelaksanaan latihannya haruslah disusun berdasarkan beberapa komponen, yaitu sebagai berikut: a) Umur, di dalam pelaksanaan latihan senam jantung sehat harus dilakukan pengelompokkan menurut umur. Hal ini dikarenakan kemampuan individual dari masing masing tingkatan umur tidaklah sama, b) Jenis Kelamin, program latihan untuk pria dan wanita haruslah berbeda, c) Kapasitas Aerobik, program latihan disesuaikan dengan kemampuan aerobic perorangan. Adalah wajib mengukur kemampuan aerobic sebelum melakukan program latihan, d) Dosis Latihan, kita ketahui bahwa kemampuan setiap orang tidak sama, maka dosis perorangan harus sesuai dengan kemampuannya, serta diberikan pada daerah aman, artinya tidak membahayakan, tetapi tetap memberi manfaat. e) Program Berencana, senam jantung sehat mempunyai target sasaran, maka program latihan haruslah direncanakan bertahap, yang akhirnya mencapai taraf pemeliharaan. Secara singkat program latihan mengikuti pola: program awal, program kondisi, danprogram pemeliharaan.

Di dalam upaya mencapai sasaran tersebut, untuk tahap pertama, semua anggota diarahkan mampu menyelesaikan program dasar, atau program aerobic sederhana sebagai inti, yaitu: 1) jalan kaki 6,4 km dalam waktu 1 jam, 2) jogging atau jalan diselingi lari 4,8 km dalam waktu 30 menit, 3) lari 3,2 km dalam waktu 20 menit.

Para anggota yang telah mampu melaksanakan program butir (1) serta usianya 40 tahun sampai 49 tahun, dapat mencoba program butir (2) yaitu jogging (andaikata syarat-syarat untuk itu dipenuhi). Untuk yang berusia di bawah 40 tahun, jelas program butir (2) harus pula dikuasai atau ditargetkan. Para anggota yang telah menyelesaikan program butir (2) serta usianya di bawah 30 tahun, dapat meningkatkan program latihan butir (3) yaitu lari $3,2 \mathrm{~km}$ dalam waktu 16 - 20 menit.

Maka setiap orang yang ingin berolahraga senam jantung sehat dapat melakukan programnya sesuai dengan umur dan kemampuannya. Di samping itu harus menguasai teknik-teknik dasar senam jantung sehat, seperti: a) menghitung denyut nadi secara tepat dan terampil, b) mengusai teknik peregangan/pemanasan/pendinginan, c) menguasai senam kelentukan yang benar, d) menguasai teknik jalan, jogging atau lari dengan benar sesuai program latihan yang dipilih atau peruntukkannya, e) mengetahui dosis/takaran latihan bagi dirinya secara tepat, f) mengetahui kapan olahraga harus dihentikan, g) mampu mengenali dan mengatasi bahaya/kegawatan (SJS seri I, 2003).

Kebugaran tubuh dapat dicapai jika olahraga yang dilakukan dapat mencapai sasaran berbagai komponen kebugaran. Misalnya, kebugaran jantungparu dapat dicapai dengan senam jantung sehat; suatu latihan yang melibatkan otot-otot besar (utamanya lengan dan tungkai) melakukan gerakan ritmis secara terus menerus. Selengkapnya regimen yang dianjurkan khususnya untuk usia lanjut adalah : a) 2 s/d 3 kali per minggu, b) memacu jantung hingga target heart rate/denyut jantung latihan, c) berjalan, jogging, berlari, senam jantung, bersepeda, lompat tali, aerobic, d) 20 - 40 menit (Santoso, 2008).

Senam jantung sehat yang telah dilakukan diharapkan akan mempunyai nilai tambah dalam bentuk pengetahuan sehingga menghasilkan sikap yang baik, seperti: 1) tidak merokok, 2) menjaga keseimbangan tinggi dan berat badan, 3) menjaga dan mengatasi faktor resiko lainnya yang ada, seperti kadar lemak dalam darah/kolesterol, tekanan darah tinggi, diabetes militus, 4) menjaga keseimbangan antara anggota dan sesama manusia, 5) selalu taat menjalakan agamanya, sehingga mencapai ketentraman lahir dan batin.

Menurut supriadi (2006) Untuk mengetahui apakah seseorang dapat dikatakan telah berhasil mencapai program latihan, dapat dipakai bebrapa tolok ukur/parameter, antara lain sebagai berikut: 1) program latihan tercapai, Berat dan tinggi badan seimbang, 2) tekanan darah normal atau terkendali, 3) denyut nadi istirahat semakin bertambah lambat (relatif bradikardi), 4) keluhan semakin hilang, 5) jumlah hari sakit berkurang, 6) faktor resiko hilang atau terkendali, 7) tingkat kesegaran jasmani baik.

\section{Senam Jantung Sehat}

Rangkaian gerak senam jantung sehat sebagai bagian dari olahraga jantung sehat, disusun dengan selalu mengutamakan klemampuan jantung, gerakan otot besar dan kelentukan sendi, serta upaya memasukkan oksigen sebanyak mungkin (SJS seri I, 2003). Bagi anggota yang lebih muda, gerakan jalan di tempat dapat ditingkatkan menjadi lari di tempat atau mengangkat kaki lebih tinggi, misalnya untuk usia 30 tahun ke bawah atau usia 40 tahun tetap berlatih. Bagi anggota yang lebih tua, usia 50 tahun ke atas, gerakan jalan di tempat cukup memacu jantung agar mencapai sasaran. Tinggi kaki disesuaikan dengan hasil latihan, bisa lebih rendah atau lebih tinggi. Di dalam menyusun senam jantung sehat telah dimasukkan prinsip latihan (Wisit, 2012), yaitu: a) Latihan peregangan / pemanasan, ketukan musik 130 ketukan / menit selama 6 menit, b) Latihan inti, ketukan musik 145 ketukan / menit selama 12 menit, c) Latihan pendinginan / 
penenangan, ketukan musik 120 ketukan / menit selama 4 menit 30 detik.

Sebelum senam, melakukan pemanasan pemanasan kecil, seperti jogging, jalan di tempat agar suhu tubuh naik. Selain itu, agar tubuh tidak kaku sehingga kemungkinan cedera diperkecil. Berdoa dulu sebelum melakukan senam. Dilakukan di luar ruangan agar ada udara segar. Sebaiknya dilakukan beramai - ramai agar lebih semangat (Santoso, 2008).

\section{Petunjuk Pelaksanaan Senam Jantung Sehat}

Penyusunan gerakan senam jantung sehat didasarkan pada prinsip dasar olahraga yang berguna untuk pembinaan kesehatan jantung dan kesegaran jasmani yang mencakup beberapa komponen, yaitu sebagai berikut : a) peningkatan ketahanan jantung dan alat peredaran darah serta pernafasan/paru (cardiorespiratory endurance), b) kekuatan otot (strength), c) ketahanan otot (muscle endurance), d) kelenturan (flexibility), e) koordinasi gerak (coordination), f) kelincahan (agility), g) keseimbangan (balance)

Sedangkan prinsip dasar pelaksanaan gerak dari senam jantung sehat baik itu seri I, II, III, IV, V maupun VI adalah melalui tahapan latihan sebagai berikut:

\section{a. Sikap Sempurna}

Sikap sempurna adalah berdiri tegak, kedua tumit rapat, ujung jari terbuka selebar kepalan tangan 5 (lima) titik, mulai dari telinga, bahu, pinggul, lutut dan mata kaki merupakan satu garis lurus, tegak lurus dengan lantai. Pandangan lurus ke depan dan kedua lengan lurus di samping badan, telapak tangan menghadap ke dalam, jari-jari tangan rapat di samping badan serta tangan tidak dikepal. Siap untuk olahraga.

\section{b. Berdoa}

Berdoa dilakukan menurut agama dan kepercayaannya masing-masing, semoga olahraga yang segera dilakukan memberi manfaat kekuatan dan kesehatan lahir dan batin. Pusatkan pikiran dan perasaan dalam suasana gembira. Setelah aba - aba "berdoa mulai", tundukkan kepala dan setelah aba-aba "berdoa selesai", kepala kembali tegak.

\section{c. Menghitung Denyut Nadi}

Menghitung denyut nadi dilakukan dengan cara jari telunjuk dan jari tangan kanan meraba nadi radialis lengan kiri (pergelangan tangan kiri) selama 10 (sepuluh) detik dan jumlahnya dikalikan 6, berarti nadi satu menit, dengan sikap dua pergelangan tangan satu jengkal di depan dada menghadap ke dalam.

Ada beberapa macam cara penghitungan denyut nadi, yaitu: 1) denyut nadi istirahat, biasanya tidak melebihi 100 kali per menit, 2) denyut nadi pemanasan, biasanya tidak melebihi 120 kali per menit, 3) denyut nadi latihan: (a) Minimal $=(3 / 4 \mathrm{x}$ nadi maksimal) per menit, (b) Optimal $=$ (nadi maksimal - 10) per menit, (c) Maksimal $=(200-$ umur) per menit (Supriyadi, 2006).

\section{Kapasitas Vital Paru}

Organ tubuh yang memiliki peran penting dalam proses pernafasan adalah paru-paru yang berfungsi untuk pertukaran gas oksigen dan karbondioksida. (Evelyn. Pearce, 1993: 219). Paru pada manusia berjumlah sepasang yaitu paru kanan dan paru kiri. Paru kanan terbagi menjadi dua fisura dan tiga lobus : superior, media, dan inferior. Paru kiri dibagi menjadi satu fisura dan dua lobus: superior dan inferior. Unit paru adalah bronkiolus dan alveolus.

Kapasitas Vital Paru adalah volume udara yang dapat diekspirasikan setelah inspirasi maksimal. (Soegiyanto, 1989 : 74). Ahli lain mengartikan Kapasitas vital paru adalah hawa yang keluar masuk apabila melakukan pernafasan secara maksimal. (Oktia Woro Kasmini Handayani, 1999 : 21). Kapasitas Vital Paru adalah jumlah udara (sekitar $4500 \mathrm{ml}$ ) yang dapat dikeluarkan oleh usaha volunter setelah inspirasi dalam. (John. Gibson, 2002: 149). Kapasitas Vital Paru terbesar yang dapat dicapai seseorang adalah pada posisi berdiri yang disebabkan oleh kecenderungan isi perut untuk menolak diafragma ke depan sehingga volume udara dalam paru-paru besar sehingga udara yang ditampung banyak.

Besarnya daya muat udara oleh paru $4500 \mathrm{ml}$ sampai $5000 \mathrm{ml}$ dan hanya sebagian kecil dari udara ini, kira-kira 1/10 atau hanya $500 \mathrm{ml}$ adalah udara pasang surut (tidal air) yaitu yang dihirup masuk dan dihempaskan keluar pada pernafasan biasa dengan tenang. Antara perempuan dan lakilaki terdapat perbedaan, bila laki-laki kapasitas normalnya 4-5 liter sedangkan untuk perempuan 3-4 liter. (Evelyn, C. Pearce, 1993: 221)

\section{Pentingnya Volume dan Kapasitas Paru}

Ada beberapa volume paru yang dapat dipergunakan untuk mengukur fungsi paru, antara lain Kapasitas Vital Paru yang merupakan gabungan dari volume cadangan inspirasi ditambah tidal volume dan volume cadangan ekspirasi. Kapasitas vital dipengaruhi oleh posisi tubuh, kekuatan otototot pernafasan dan kemampuan paru dan rongga untuk berkembang. Pentingnya meningkatkan kapasitas vital paru adalah erat kaitannya dengan penyediaan $\mathrm{O} 2$ untuk berlangsungnya proses oksidasi di dalam sel.

\section{Pengukuran Kapasitas Vital Paru}

Kapasitas vital paru diukur dengan menggunakan alat spirometer (Evelyn, C. Pearce, 1993: 221). Spirometer yang digunakan adalah spirometer dari Hutchinson dengan skala $500 \mathrm{ml}$ sampai $7000 \mathrm{ml}$. 
Cara penggunaan spirometer ini adalah pertamatama masukkan air pada tabung Hutchinson sebatas garis merah kemudian sesuaikan keleb batas dengan suhu air yang terbaca di termometer, bersihkan corong hembusnya dengan alkohol. Hal ini dilakukan juga setiap kali berganti yang menggunakan yaitu harus dibersihkan dengan alkohol. Lepas dan buka jentik pengunci yang menhan putaran tabung, sehingga apabila udara dihembuskan ke dalam tabung maka tabung dapat berputar setelah testee siap, testee menghirup udara sebanyak-banyaknya dan hembuskan udara kuat-kuat pada corong hembusnya tanpa ada bocoran udara sampai testee tidak dapat lagi mengeluarkan udara dari paru-paru. Setelah tabung berhenti berputar maka barulah dibaca kemampuan kapasitas vital paru testee pada skala penunjuk, kemudian hasil pengukuran yang terbaik yang merupakan hasil akhir.

\section{Wanita Usia Lanjut}

Wanita adalah (orang) perempuan (lebih halus). (Poerwadarminta,1984: 1147). Usia lanjut adalah mereka yang berusia 55 tahun ke atas (Emma S. Wirakusumah, 2002: 5). Jadi wanita usia lanjut adalah perempuan yang berusia di atas atau sama dengan 55 tahun.

Mereka yang telah memasuki usia lanjut akan mengalami penurunan fungsi organ yang dapat berpengaruh terhadap kemampuan melakukan aktivitas kerja. Hal ini terjadi pula pada organ paru, yang mengalami penurunan fungsi akibat berkurangnya elastisitas serabut otot yang mempertahankan bronkiolus tetap terbuka (Emma S. Wirakusumah, 2002: 27).

\section{Olahraga dan Kebugaran Untuk Usia Lanjut}

Pada usia lanjut terjadi penurunan masa otot serta kekuatannya, laju denyut jantung maksimal, toleransi latihan, kapasitas aerobik dan terjadinya peningkatan lemak tubuh sehingga seseorang dengan aktivitas fisik rendah mempunyai resiko yang lebih tinggi menghadapi kematian lebih awal.

Sasaran latihan fisik untuk usia lanjut adalah fleksibilitas dan kekuatan otot, salah satu contohnya adalah latihan Senam Sehat Indonesia. Dengan latihan Senam Sehat Indonesia maka kaum usia lanjut diharapkan dapat memelihara kesehatan dan kesegaran jasmaninya. Usia lanjut yang tetap aktif juga dapat membangkitkan rasa kemampuan dan rasa percaya diri mereka untuk menunjang hidup sehat. Latihan olahraga untuk usia lanjut sifatnya aerobik yang bertujuan untuk meningkatkan kesegaran jasmani.dengan ciri-ciri latihan: Durasi waktu latihan lebih dari 12 menit. Intensitas sedang dengan DN 75\%-80 \% dari denyut nadi maksimal. Frekuensi 3 kali seminggu. Harus melibatkan banyak otot badan. (Sugiyanto dan Sudjarwo, 1991: 200).

\section{METODE}

Metode dalam penelitian ini adalah metode eksperiment dengan jenis pre-test and post-test group design yang terdiri dari pre- test, treatment dan post-test. Populasi dalam penelitian ini adalah pensiunan wanita usia di P2TEL Medan dengan jumlah 52 orang. Adapun sampel penelitian ini berjumlah 30 orang yang diperoleh dengan menggunakan teknik random.

\section{HASIL DAN PEMBAHASAN}

Hasil penelitian ini merupakan hasil pengukuran kapasitas vital paru pensiunan wanita P2TEL Medan sebelum dan sesudah mengikuti latihan Senam Jantung Sehat Seri I tahun 2019. Pengukuran dilakukan pada 30 orang pensiunan wanita yang berusia lanjut (berusia diatas atau sama dengan 55 tahun).

Tabel 1. Distribusi Frekuensi Sampel Penelitian

\begin{tabular}{|c|c|c|c|}
\hline No & Umur & F & \% \\
\hline 1 & $55-60$ & 11 & 36.67 \\
\hline 2 & $61-65$ & 8 & 26.67 \\
\hline 3 & $66-70$ & 8 & 26.67 \\
\hline 4 & $71-75$ & 3 & 10.00 \\
\hline & Jumlah & 30 & 100.00 \\
\hline
\end{tabular}


Tabel 2. Rata-Rata Kapasitas Vital Paru Hasil Pengukuran Sebelum Mengikuti Latihan Senam Jantung Sehat Seri I

\begin{tabular}{|l|r|}
\hline & \multicolumn{1}{|c|}{$\begin{array}{c}\text { Kapasitas vital paru } \\
\text { sebelum mengikuti senam } \\
\text { sehat Indonesia }\end{array}$} \\
\hline Minimum & 500.00 \\
Maximum & 1500.00 \\
Mean & 946.0000 \\
Std. Deviation & 259.2376 \\
Variance & 67204.138 \\
\hline
\end{tabular}

Tabel 3. Rata-Rata Kapasitas Vital Paru Hasil Pengukuran Setelah Mengikuti Latihan Senam Jantung Sehat Seri I

\begin{tabular}{|l|r|}
\hline & \multicolumn{1}{|c|}{$\begin{array}{c}\text { Kapasitas vital paru } \\
\text { setelah mengikuti senam } \\
\text { sehat Indonesia }\end{array}$} \\
\hline Minimum & 620.00 \\
Maximum & 1600.00 \\
Mean & 1013.3333 \\
Std. Deviation & 284.1240 \\
Variance & 80726.437 \\
\hline
\end{tabular}

Berdasarkan data tabel 1 diketahui terdapat $36,67 \%$ responden berumur antara 55-60 tahun, $26,67 \%$ antara 61-65 tahun, 26,67\% antara 66-70 tahun dan $10 \%$ antara 71-75 tahun. Tabel 2 menunjukkan rata-rata kapasitas vital paru sebelum mengikuti latihan Senam Jantung Sehat Seri I mencapai $946 \mathrm{ml}$ dengan standar deviasi 259,2376. Hal ini menunjukkan bahwa kapasitas vital paru sebelum mengikuti latihan senam jantung sehat seri I bervariasi dengan kapasitas vital paru terendah $500 \mathrm{ml}$ dan tertinggi $1500 \mathrm{ml}$.

Terlihat dari tabel 3 bahwa kapasitas vital paruparu setelah mengikuti latihan Senam Jantung Sehat Seri I juga bervariasi dengan kapasitas vital paru terendah $620 \mathrm{ml}$ dan tertinggi $1600 \mathrm{ml}$. Untuk mengetahui peningkatan kapasitas vital paru setelah mengikuti latihan Senam Jantung Sehat Seri I dapat dilihat dari uji t seperti pada tabel 4.

Tabel 3. Uji Hipotesis

\begin{tabular}{|c|c|c|c|c|c|}
\hline Kapasitas Vital Paru & Rata-rata & Peningkatan & Thitung & $T_{\text {tabel }}$ & Keterangan \\
\hline Sebelum Latihan & 946.00 & \multirow[b]{2}{*}{$7.12 \%$} & \multirow[b]{2}{*}{3.68} & \multirow[b]{2}{*}{2.46} & \multirow[b]{2}{*}{ Ho ditolak } \\
\hline Sesudah Latiham & 1013.33 & & & & \\
\hline
\end{tabular}

Keterangan:

Ho $: \mu_{1} \geq \mu_{2} \quad$ (Tidak meningkat)

Ho $: \mu_{1}<\mu_{2}$ (terjadi peningkatan)

Berdasarkan hasil uji t ( t a be 13 ) diperoleh nilai thitung sebesar $3,68>$ tabel $(2,46)$ pada taraf signfikansi 0,01 yang berarti Ho dengan pernyataan tidak ada peningkatan kapasitas vital paru ditolak, sedangkan Ha dengan pernyataan ada peningkatan kapasitas vital paru pensiunan wanita P2TEL Medan diterima dengan peningkatan sebesar $7,12 \%$.

Berdasarkan hasil penelitian menunjukkan bahwa ada peningkatan yang signifikan kapasitas vital paru pada pensiunan wanita setelah mengikuti latihan Senam Jantung Sehat Seri I di P2TEL 
Medan. Terjadinya peningkatan kapasitas vital paru pensiunan wanita disebabkan karena respons tubuh secara faal yaitu menebalnya otot- otot diafragma yang mengakibatkan proses respirasi dapat dilakukan secara maksimal. Latihan senam jantung sehat seri I menggunakan metode latihan pernafasan diafragma.

Menurut Dr. T Nakamura dalam Baranas SSI, pernafasan dengan diafragma menyebabkan volume $\mathrm{O}_{2}$ yang masuk ke paru-paru lebih banyak sehingga jantung dapat memompa darah lebih banyak (1989: 4). Latihan pernafasan inilah yang memberikan kontribusi yang nyata terhadap peningkatan kapasitas vital paru bagi pensiunan wanita usia lanjut di P2TEL Medan Tahun 2019. Dalam Senam Jantung Sehat Seri I, terdapat unsurunsur latihan yaitu latihan peregangan, latihan meningkatkan kelenturan sendi, latihan balance dan koordinasi yang bermanfaat untuk menguatkan fungsi sistem lokomotor yaitu sendi tulang, otot dan saraf tepi.

\section{KESIMPULAN}

Berdasarkan hasil penelitian dapat diambil kesimpulan bahwa: 1) Latihan Senam Jantung Sehat Seri I dapat mempengaruhi peningkatan kapasitas vital paru pensiunan wanita P2TEL Medan. 2) Latihan Senam Jantung Sehat Seri I memberikan kontribusi yang signifikan terhadap peningkatan kapasitas vital paru pensiunan wanita P2TEL Medan, yaitu sebesar 7,12\%. Adapun saran yang dapat disampaikan agar pensiunan wanita P2TEL Medan untuk lebih termotivasi dalam melakukan kegiatan Senam Jantung Sehat Seri I sebagai salah satu bentuk latihan pembinaan kondisi fisik yang prima dalam menjaga tingkat kesegaran jasmani.

\section{REFERENSI}

Ambardini, Rachmah. 2009. Aktivitas Fisik Pada Lanjut Usia. Yogyakarta: Universitas Negeri Yogyakarta

Cerika, Rismayanthi. 2009. Pengaruh Senam Jantung Sehat Indonesia Terhadap Penurunan Tekanan Darah Pada Penderita Hipertensi. Tesis. Yogyakarta: Program Pasca Sarjana Universitas Negeri Yogyakarta.

Emma S. Wirakusumah. 2002. Tetap Bugar Di Usia Lanjut. Jakarta: Trubus Agriwidya

Kusmana, Dede. 2006. Olahraga Untuk Orang Sehat dan Penderita Penyakit Jantung. Jakarta: Balai Penerbit Fakultas Kedokteran Universitas Indonesia.

Lilik. 2011. Keperawatan Lanjut Usia. Yogyakarta: Graha Ilmu.

Pudjiastuti dan Budi Utomo. 2003. Fisioterapi pada Lansia. Jakarta: EGC.

Sugiyanto dan Sujdarwo. 1991. Perkembangan Motorik. Jakarta: Depdikbud

Yayasan Senam Jantung Sehat. 2003. Senam Jantung Sehat seri I. Jakarta: Yayasan Jantung Sehat. 